\section{CONFERENCE WILL LOOK AT THE WHOLE PERSON}

The theme for this year's British Society of Dental Hygiene and Therapy (BSDHT) Oral Health Conference and Exhibition is 'Looking Beyond the Obvious'.

The event takes place on 15 and 16 November 2013 at the International Conference Centre (ICC) in the heart of Birmingham.

BSDHT President Elect, Michaela ONeill, said: 'The days when a hygienist or therapist looked exclusively at the oral health of the patient are gone - and rightly so because that's I no longer good enough. Each patient is different, and at a different stage in their life and as clinicians we must take a broader, more holistic, approach to their care...

The Conference aims to give delegates an insight into the sorts of problems they may encounter when taking a more holistic approach and providing advice and guidance on how to overcome those problems.

To promote the theme of this year's Conference BSDHT have launched a new logo which visually depicts the journey of a tooth from literature to reinforce I the theme. Conference and Exhibition Programme I bsdht.org.uk. childhood to old age. The logo will be used in all Conference

The full are available online at www.

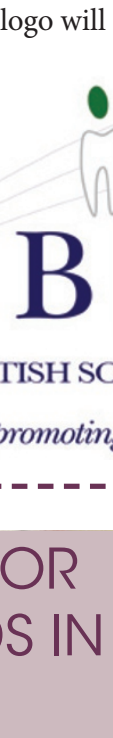

A team from Perfect 32 dental practice in Ladygate helped to spread the oral health messages of National Smile Month (NSM) with events at local primary schools involving more than 200 children.

A dentist, a practice manager and a dental nurse from Perfect 32 hosted educational workshops at Cherry Burton and Walkington Primary Schools, teaching the children about good oral health, brushing instruction using disclosing tablets and an oversized set of teeth, and running a 'bug making' competition. The team also distributed NSM goodies such as toothbrushes, toothpaste, erasers, bookmarks, balloons, stickers and the famous NSM 'Smileys' on sticks.

National Smile Month is an annual event and ran from 20 May to 20 June.

\section{COLA AS BAD FOR TEETH AS CRACK}

Excessive amounts of fizzy drinks can damage teeth as badly as methamphetamine (meth) or crack cocaine, according to a study published in General Dentistry.

In the study Dr Mohamed Bassiouny, professor of restorative dentistry at the Temple University School of Dentistry in Philadelphia says that meth, crack cocaine and fizzy drinks, whether sweetened or not, are all highly acidic and can cause similar dental problems.

The study highlights that the dentitions of individuals addicted to meth or crack cocaine can be misdiagnosed as dental caries rather than generalised dental erosion, a condition that is also associated with chronic excessive consumption of fizzy drinks. Failing to identify the causative aetiology could lead to a wrongful diagnosis that could in turn adversely affect treatment planning.

1. Bassiouny M A. Dental erosion due to abuse of illicit drugs and acidic carbonated beverages. Gen Dent 2013; 61: 38-44.

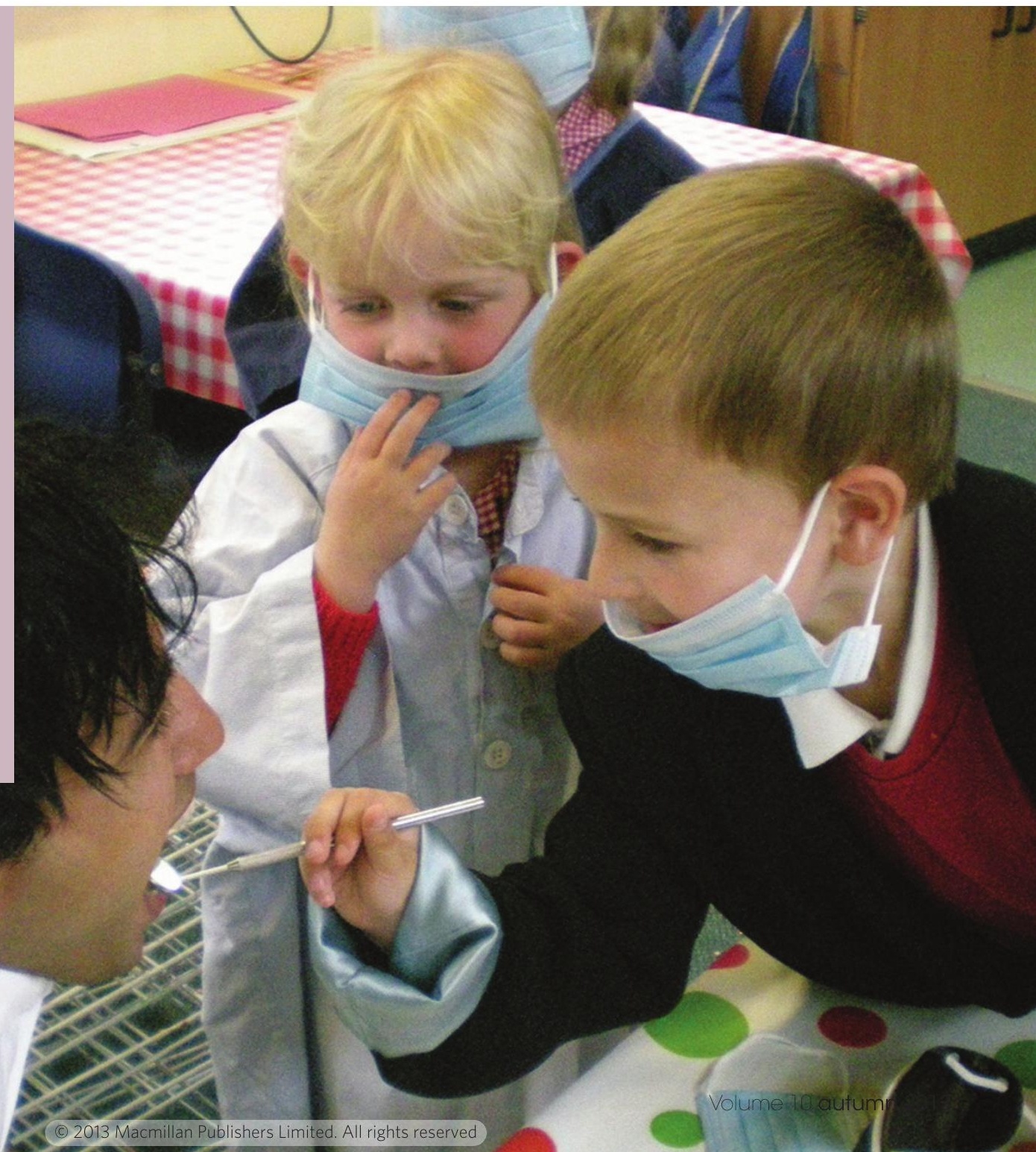

